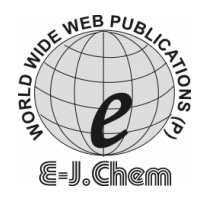

http://www.e-journals.net

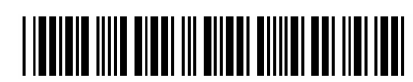

ISSN: 0973-4945; CODEN ECJHAO

E-Journal of Chemistry

2009, 6(1), 231-236

\title{
Dielectric Study on Fly Ash Blended Cement
}

\author{
G. SIVAKUMAR ${ }^{*}$, K. MOHANRAJ ${ }^{\S}$ and S. BARATHAN ${ }^{\S}$ \\ *Centralised Instrumentation and Service Laboratory (CISL), \\ Annamalai University. \\ ${ }^{\S}$ Department of Physics, Annamalai University, \\ Annamalainagar- 608 002, India. \\ gsk_cisl@yahoo.com
}

Received 19 June 2008; Revised12 September 2008; Accepted 5 November 2008

\begin{abstract}
In this paper, the hydration behaviour of ordinary portland cement (OPC) and fly ash blended cement (10, 25 and 40\%) replaced by two different fly ashes (FA) were investigated. The samples were hydrated with distilled water (DW) in water to solid ratio 0:4 and its setting time and dielectric measurement are carried out. Results of the study found that the fly ash blended cement composites have slow hydration than OPC during early stages (up to $24 \mathrm{~h}$ ).
\end{abstract}

Keywords: Dielectric Study, Fly Ash Blended Cement, OPC, Hydration behaviour.

\section{Introduction}

Supplementary cementitious materials such as blast furnace slag, silica fume and fly ash, etc. are increasingly being used in construction industry due to its technical, economical and environmental reasons ${ }^{1}$. The incorporation of various supplementary cementing materials either as ingredient in blended cement system or separately in concrete has been investigated in different countries by significant number of researchers ${ }^{2}$. This gives an encouraging result regarding the mechanical property and durability of concrete.

Presently about 112 million tonnes of coal-ash is generated in India from more than 70 thermal power plants ${ }^{3}$. By the year 2012 this is predicted to be increased to 170 million tonnes per annum. Due to huge availability of fly ash at zero price producing eco-friendly and higher strength concrete is of considerable interest in the present scenario and forms the aim of the paper.

Initial hydration kinetics of either pure or blended cement is of complex in nature. Usually physical and chemical changes of the cement paste can be well observed with electrical methods. The microwave method (dielectric) is one of the best tools to monitor the dynamics of cement hydration during early hydration ${ }^{4}$. 


\section{Cement chemistry notation}

$\mathrm{C}_{3} \mathrm{~S}$-Tricalcium silicate, $\mathrm{C}_{2} \mathrm{~S}$-Dicalcium silicate, $\mathrm{C}_{3} \mathrm{~A}$-Tricalcium aluminate, $\mathrm{C}_{4} \mathrm{AF}$-Tetra calcium alumino ferrite.

Hence, the authors preferred the microwave (dielectric) technique to monitor the hydration behaviour of pure and fly ash blended cement paste.

\section{Experimental}

American Standard for Testing Materials (ASTM), type-I ordinary portland cement (OPC) and fly ashes (FA) collected from North Chennai Thermal Power Station (F1) and Neyveli Lignite Corporation (F2), Tamil Nadu, India were used in this study and its chemical analysis are given in Table 1.

Table 1. Results of the chemical analysis (wt \%).

\begin{tabular}{lllllllllll}
\hline Composition & $\mathrm{CaO}$ & $\mathrm{SiO}_{2}$ & $\mathrm{Al}_{2} \mathrm{O}_{3}$ & $\mathrm{Fe}_{2} \mathrm{O}_{3}$ & $\mathrm{SO}_{3}$ & $\mathrm{MgO}$ & $\mathrm{Na}_{2} \mathrm{O}$ & $\mathrm{K}_{2} \mathrm{O}$ & LOI & Others \\
\hline OPC & 63.0 & 21.79 & 5.75 & 3.25 & 2.35 & 1.97 & 0.50 & 0.28 & 1.00 & 0.11 \\
Fly ash (F1) & 2.88 & 59.09 & 26.32 & 5.80 & 0.10 & 1.09 & 0.82 & 0.71 & 1.74 & 1.45 \\
Fly ash (F2) & 15.62 & 44.91 & 24.38 & 6.04 & 0.60 & 2.84 & 0.88 & 0.94 & 1.99 & 1.80 \\
\hline
\end{tabular}

From the Table 1, the $\mathrm{F} 1$ fly ash is found to be a low $\mathrm{CaO}$ fly ash (' $\mathrm{F}$ ' type) and $\mathrm{F} 2$ fly ash is found to be high $\mathrm{CaO}$ fly ash (' $\mathrm{C}$ ' type). The above two fly ashes were mixed with OPC in 10, 25 and $40 \%$ by weight replacement basis. The control (OPC) and fly ash composites (F1 and F2) were hydrated with distilled water in water to solid ratio (w/s) 0:4. Setting time of the samples is carried out using Vicat's apparatus by ASTM C 191 procedure $^{5}$ and the results are given in Figure 1.

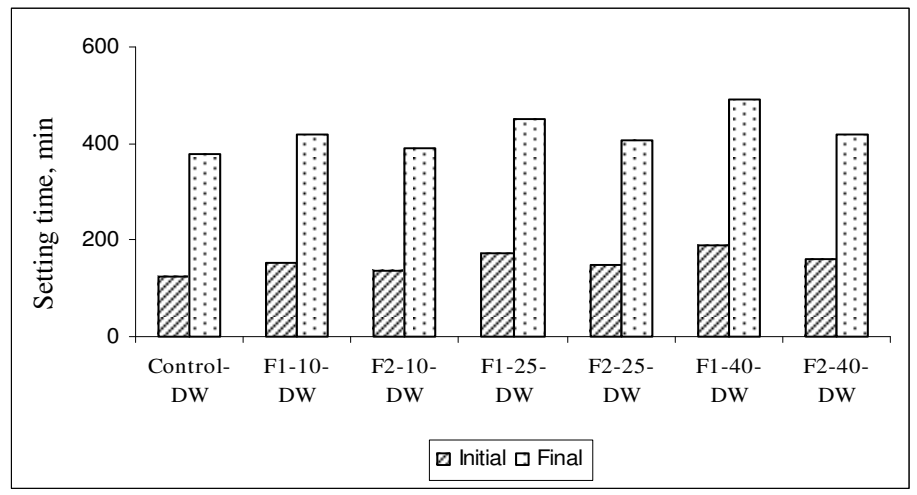

Figure 1. Setting time of control, F1 and F2 fly ash blended cement composites

From the Figure 1, the initial and final setting of control paste is observed around $2 \mathrm{~h}$ and $6 \mathrm{~h}$ respectively. In $\mathrm{F} 1$ composites (10, 25 and 40\%), the initial and final setting is observed at around 2-3 $\mathrm{h}$ and 7-8 $\mathrm{h}$ respectively whereas in F2 fly ash composites, initial and final setting values are around $2-2.5 \mathrm{~h}$ and $6.5-7 \mathrm{~h}$ respectively. It is clearly observed that as fly ash percentage increases the setting time also increases compared to control paste. However, the F2 composites have approximately 0.5 h shorter time (quick setting) than F1. It is supported by the observations of Dan Ravina and Mehta, $(1986)^{6}$. According to the author, setting time was delayed for both type fly ashes (class ' $\mathrm{C}$ ' and ' $\mathrm{F}$ ') compared with the control paste.

For dielectric measurement, the control and fly ash blended cement composites are filled in the sample holder and butted against polystyrene to avoid leakage if any. 
The measurements are made during the first $24 \mathrm{~h}$ of hydration at a frequency of $9.54 \mathrm{GHz}$ which has been selected after a pilot study. The first measurement was carried out after 5 min of hydration and is taken as zero. Further measurements are noted at every 5 min during first $10 \mathrm{~h}$ and then at an interval of $0.5 \mathrm{~h}$ over the next $14 \mathrm{~h}$. Using these observations, the real part of dielectric constant $(\varepsilon)$ are computed using $\mathrm{C}^{++}$program and the $\varepsilon$ values are plotted.

\section{Results and Discussion}

Dielectric constant $(\varepsilon) v s$ hydration time are plotted for control and fly ash (F1) blended cement composites and are shown in Figure 2.

When anhydrated cement particles are in contact with water, various simultaneous hydration processes takes place. Various alkali oxides and sulphates present in cement dissolve completely, resulting in an increase of cations and anions $\left(\mathrm{Ca}^{2+}, \mathrm{K}^{+}, \mathrm{Na}^{+}, \mathrm{SO}_{4}^{2-}\right.$ and $\left.\mathrm{OH}^{-}\right)$in the aqueous media ${ }^{7}$. The primary ions $\left(\mathrm{Ca}^{2+}\right.$ and $\left.\mathrm{OH}^{-}\right)$which were rapidly dissolved from $\mathrm{C}_{3} \mathrm{~S}$ and $\mathrm{C}_{3} \mathrm{~A}$ grain's surface causes an increase in ion concentration and forms fibrous ettringite products. During this period, most ions are unbound charges in the aqueous phases. These unbound charges being polarized moves easily in the electrical field, resulting in a large dielectric constant. Hence the initial dielectric values of control are higher up to first $15 \mathrm{~min}$ from starting of the hydration and decrease rapidly up to $1 \mathrm{~h}$ hydration. This stage is called pre-induction period.

The initial hydrolysis of cement can be represented in the pre-induction and induction period on the lines of Perez Penna et $l^{8}$, as follows,

$$
\begin{gathered}
\mathrm{C}_{3} \mathrm{~A}+6 \mathrm{H}+3 \overline{\mathrm{CSH}_{2}} \rightarrow 6 \mathrm{Ca}^{2+}+2 \mathrm{Al}\left(\mathrm{OH}^{-}\right)_{4}+3 \mathrm{SO}_{4}^{2-}+4(\mathrm{OH}) \\
6 \mathrm{Ca}^{2+}+2 \mathrm{Al}\left(\mathrm{OH}^{-}\right)_{4}+3 \mathrm{SO}_{4}^{2-}+4 \mathrm{OH}^{-} \rightarrow \mathrm{C}_{6} \overline{\mathrm{AS}}_{3} \mathrm{H}_{32} \text { (Ettringite) } \\
\mathrm{C}_{3} \mathrm{~S}+\mathrm{H}_{2} \mathrm{O} \rightarrow \text { " } \mathrm{C}_{2} \mathrm{~S}^{\prime}+\mathrm{Ca}^{2+}(\mathrm{aq})+\mathrm{OH}^{-} \text {(aq) }
\end{gathered}
$$

In the period between 1 and 6 hour, the $\varepsilon$ value continues to decrease in a slow rate. This period is called as induction period. During the induction period, the dissolved $\mathrm{Ca}^{2+}$ and $\mathrm{OH}^{-}$ ions leaves behind a surface layer rich in hydro silicate ions on the $\mathrm{C}_{3} \mathrm{~S}$ and $\mathrm{C}_{3} \mathrm{~A}$ phase, giving the cement grain a net negative charge. During the same period, amorphous, semi-permeable gel membrane of $\mathrm{CSH}$ forms outside the surface layer. This surface layer together with the grain and CSH forms an electrical double layer, resulting in a physical barrier separating the silica-rich surface layer and the diffused electrical double layer. The electrical double layer hinders the rapid dissolution of anhydrated cement grains, leading to a slow hydration rate during this period ${ }^{9}$. Also, $\mathrm{Si}^{4+}$ ion concentration decreases, whereas $\mathrm{Ca}^{2+}$ ion concentration increases and reaches a super saturation level. Hence, early hydration products of calcium hydroxide $(\mathrm{CH})$ and Calcium silicate hydrate (CSH) nuclei begin to form (Eq.4).

$$
\text { “ } \mathrm{C}_{2} \mathrm{~S} "+\mathrm{Ca}^{2+}{ }_{(\mathrm{aq})}+\mathrm{OH}_{(\mathrm{aq})}^{-} \rightarrow \text { " } \mathrm{C}_{2} \mathrm{~S} "+\mathrm{Ca}(\mathrm{OH})_{2}
$$

The formation of these products causes a continuous increase in viscosity of the cement paste. This results in a difficult polarization and moment of the charged ions leading to a decrease in $\varepsilon$ of the cement paste. End of the induction period is coincides with the setting observations.

In the period 6-15 h, the $\varepsilon$ gets decreased in a faster rate indicating the formation of $\mathrm{CH}$ and $\mathrm{CSH}$ products and also the ettringite products subsequent transformation to monosulphates occur (eqn.5).

$$
\begin{array}{cc}
2 \mathrm{C}_{3} \mathrm{~A}+\mathrm{C}_{6} \overline{\mathrm{AS}}_{3} \mathrm{H}_{32} & \rightarrow 3 \mathrm{C}_{4} \overline{\mathrm{AS}} \mathrm{H}_{12} \\
\text { (Ettringite) } & \text { (Monosulphate) }
\end{array}
$$




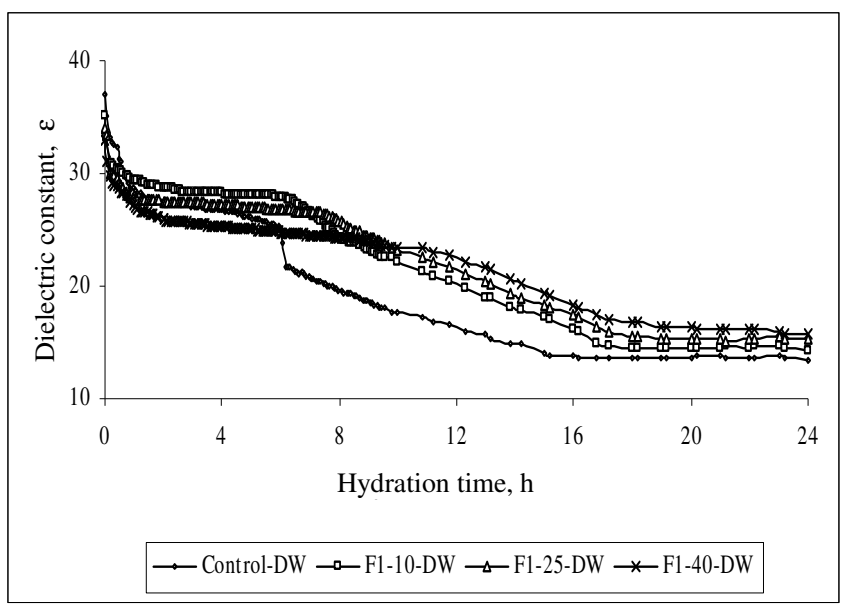

Figure 2. Dielectric constant $v s$ hydration time plot for control and F1 fly ash blended cement composites hydrated with DW

During this period, rupturing of electrical double layer occurs and allows water to reach the cement grains leading to an accelerated dissolution of the cement grains. While $\mathrm{Ca}^{2+}$ ions are removed from solution, cement hydration products are rapidly increased in this period. As the hydration products build up on the cement grains, the CSH extends forming a fibrous rigid structure.

After $15 \mathrm{~h}$, the $\varepsilon$ values decrease in a linear fashion. This period is called deceleration period. During this period, a slow diffusion controlled formation of $\mathrm{CSH}$ and $\mathrm{CH}$ takes place. The polar molecules and ions are locked in pores and find it difficult for the contribution of polarization and hence a decrease in polaraizability of cement paste occurs, increasing the hydration products with an increase in porosity resulting in a decrease of $\varepsilon$ values.

Changes of the dielectric values of fly ash (F1 and F2) blended cement composites seems to be similar as that of control paste. In F1-10\% composite, the initial $\varepsilon$ values are lesser (first $15 \mathrm{~min}$ ) than control paste but with the same decreasing trend within $1 \mathrm{~h}$. From $1 \mathrm{~h}$ onwards, the change $\varepsilon$ are slow in $10 \%$ up to $7 \mathrm{~h}$, extending the induction period compared to control. It may be due to fly ash particles retarding the hydration of OPC. According to Zhang et al., the fly ash act almost as an inert filler in the blend during the early stage of hydration ${ }^{10}$ as observed from their dielectric measurement. Similar result holds good in the present study. After the induction period, the $\varepsilon$ values decrease in a faster rate up to $16.5 \mathrm{~h}$.

After $16.5 \mathrm{~h}$ and till the end of the investigation period a linear variation of $\varepsilon$ values is observed with a higher value than control paste.

In $25 \%$ and $40 \%$, it is observed that as fly ash percentage increases a drop in initial $\varepsilon$ value with a rapid decrease up to $1 \mathrm{~h}$ similar as that of $10 \%$ composites. The variation in the rate of decrease of $\varepsilon$ in the region (induction period) 1-7.5 $\mathrm{h}$ and $1-8 \mathrm{~h}$ are very slow and extended to longer time compared to $10 \%$ composite. This indicates that, when fly ash percentage increase, the induction period is extended denoting an extension of setting time and consequently a delay in nucleation and crystallisation process. In other words, as cement content decreases, the rate of hydration also decreases. According to Zhang et al., the induction period is depending on composition of cementitious materials ${ }^{9}$. After the induction period a rapid decrease in the $\varepsilon$ values is observed up to $16.5 \mathrm{~h}$. At the end of 
hydration time, a slow rate of decrease $(24 \mathrm{~h})$ and a higher $\varepsilon$ value is observed in $40 \%$ followed by $25 \%$ and $10 \%$ composite.

Figure 3 shows the dielectric constant $v s$ hydration time plot for F2 fly ash blended cement composites. The initial $\varepsilon$ value is higher and decrease rate is higher up to $1 \mathrm{~h}(10,25$ and $40 \%)$ than F1 composites. This indicates that the fly ash (F2) accelerates the hydration compared to F1 fly ash. This may be due to a higher $\mathrm{CaO}$ content which reacts faster and produce more $\mathrm{Ca}^{2+}$ ions. According to Malhotra and Ramezanianpour, the high $\mathrm{CaO}$ fly ashes have self cementing properties and fast reaction in early periods ${ }^{11}$. This hold true in their studies.

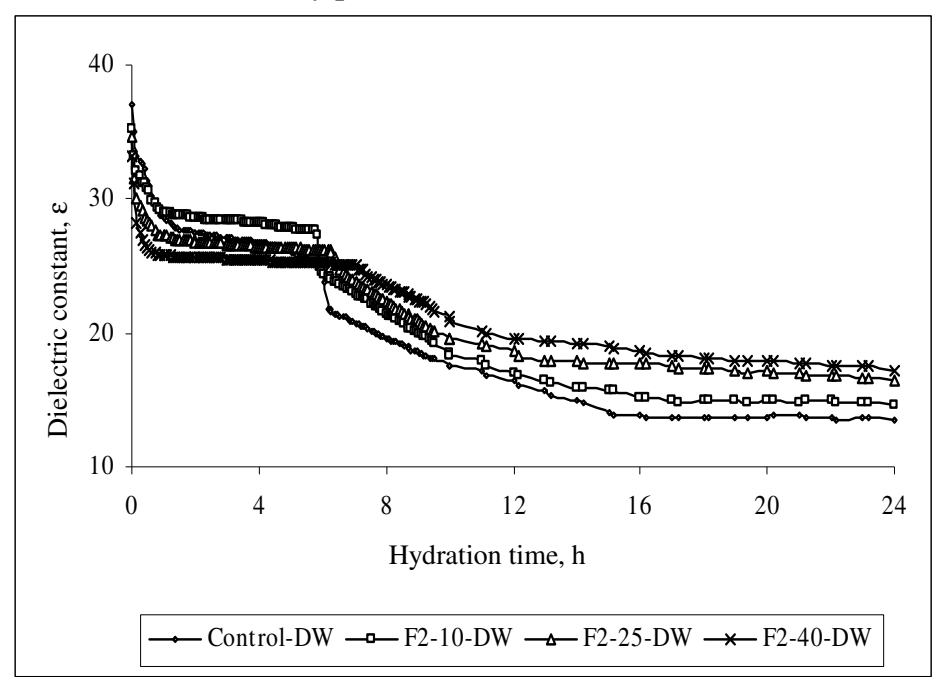

Figure. 3. Dielectric constant $v s$ hydration time plot for control and F2 fly ash composites hydrated with DW

The induction period was observed between 1 and $7 \mathrm{~h}$ for all the three percentages of FA. This is very shorter (approx. $0.5 \mathrm{~h}$ ) than F1 fly ash composites. This indicates that, the hydration products are being formed very quickly followed by control paste. After the induction period, a fast decreases between 7 and $16.5 \mathrm{~h}$ is observed. After $16.5 \mathrm{~h}$ i.e., the end of the investigation period, the $\varepsilon$ values are lesser than F1 fly ash composite but slightly higher than control. The results show that the F2 fly ash acts as almost a direct cementitious material. According to Wei Fajun et al., class ' $C$ ' and ' $F$ ' type fly ashes retard type I cement hydration up to $24 \mathrm{~h}^{12}$. This is supported by the present study also.

\section{Conclusion}

- The change in dielectric values reflects the chemical reaction with setting time during early hydration $(24 \mathrm{~h})$.

- Compared to control, the fly ash blended cement composites extend the induction period by the delayed formation of hydration products.

- The induction period is shortened in F2 composites than F1, and coincides with the setting time observation. This is due high $\mathrm{CaO}$ content.

- The setting time measured with Vicat's apparatus supplement the dielectric observations. Hence dielectric reading is a suitable technique for the study of hydration behaviour of cementitious system. 


\section{References}

1. Papadakis V G and Tsimas S, Chem Concr Res., 2002, 32, 1525.

2. Hassan K E, Cabrera J G and Maliehe R S, Chem Concr Compo., 2000, 22, 267.

3. Snigdha Sushil and Vidya S Batra, Fuel, 2006, 85, 2676.

4. Barathan S, Govindarajan D, Sivakumar G and Raghu K, Indian J Pure Appl Phys., 2006, 44, 334.

5. Lee W K W and Van Deventer J S J, Chem Concr Res., 2002, 32, 577.

6. Dan Ravina and Mehta P K, Chem Concr Res., 1986, 16, 227.

7. Dražan Jozić and Jelica Zelić, Ceramics - Silikáty., 2006, 50(2), 98.

8. Perez Penna M, Roy DM and Tamás FD, J Mater Res., 1989, 4(1), 215.

9. Zhang X, Ding X Z, Ong CK and Tan BTG, J Mater Sci., 1996, 31, 1345.

10. Zhang, Yang X Y, Wong C L and Ong C K, J Mater Sci., 1998, 33, 4191.

11. Malhotra V M and Ramezanianpour A A, Fly ash in concrete, $2^{\text {nd }}$ Ed., CANMET, Canada Centre for Mineral and Energy Technology, 1994, 18.

12. Wei Fajun, Michael W.Grutzeck and Della M.Roy, Chem Concr Res., 1985, 15, 174. 


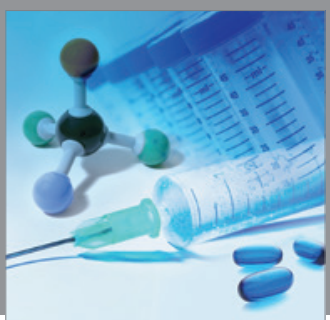

International Journal of

Medicinal Chemistry

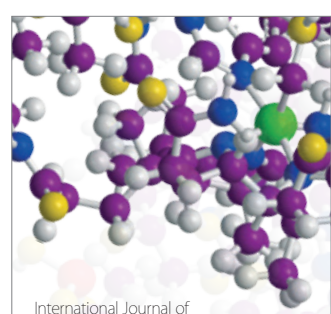

Carbohydrate Chemistry

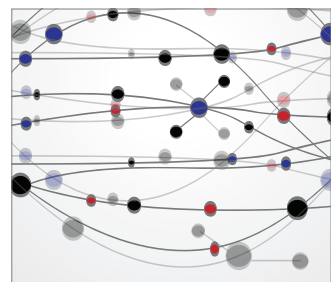

The Scientific World Journal
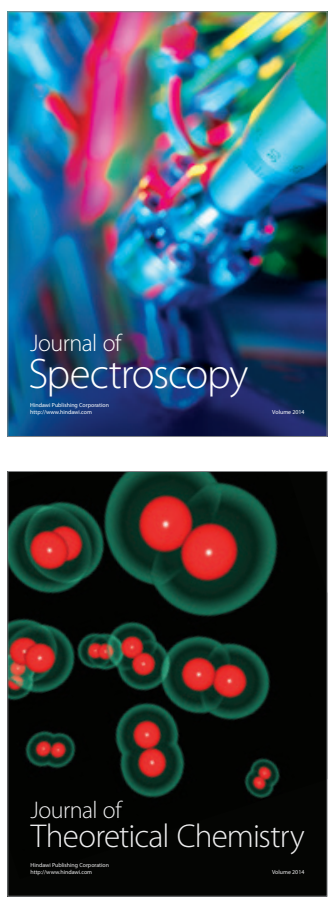
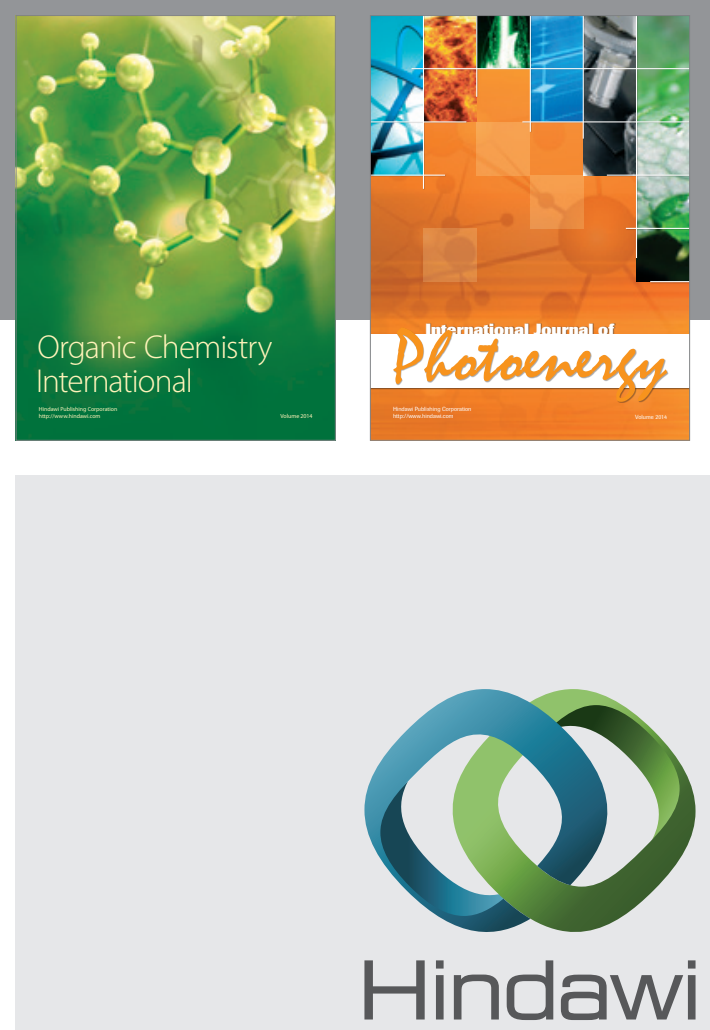

Submit your manuscripts at

http://www.hindawi.com
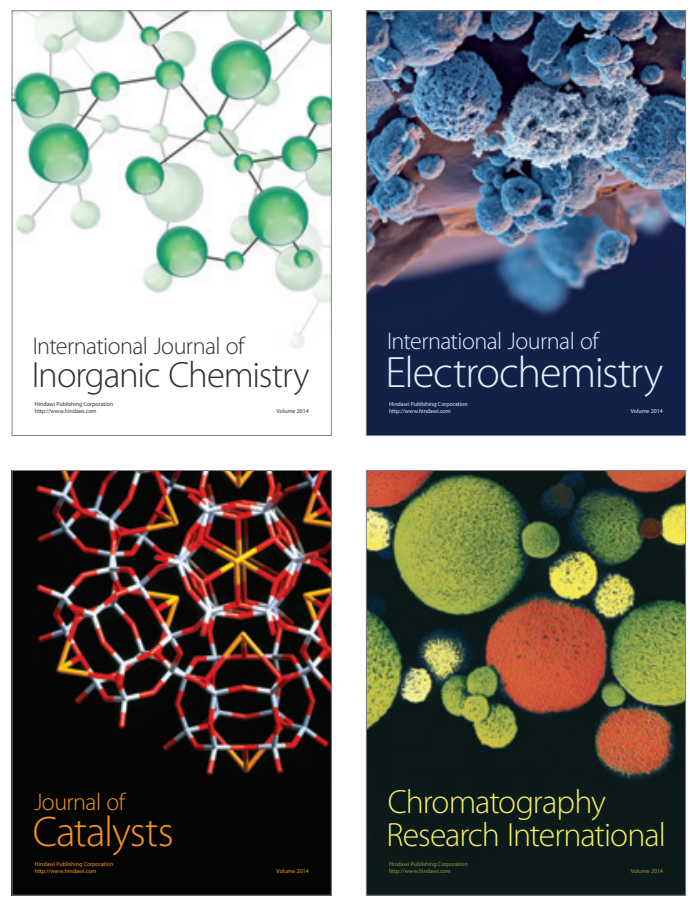
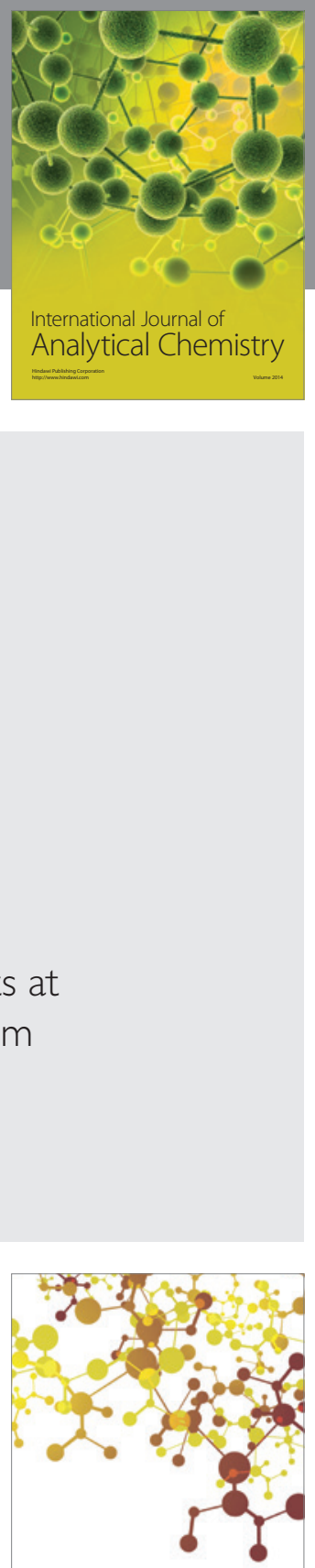

Journal of

Applied Chemistry
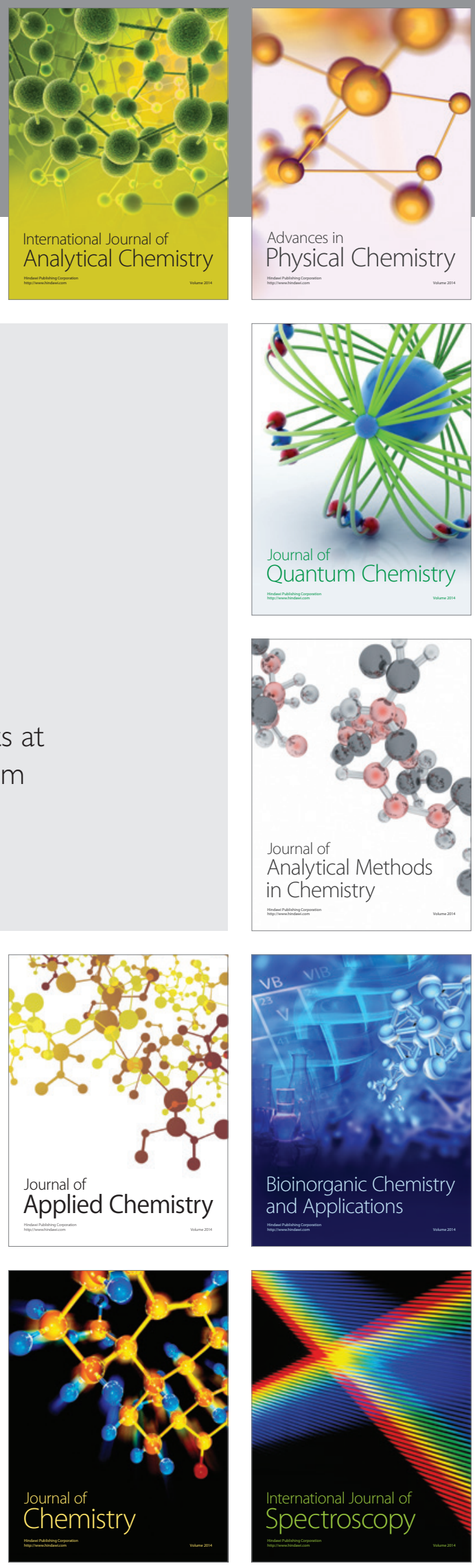